\title{
Inclusive pedagogy and knowledge in special education: addressing the tension
}

\author{
Joseph Mintz* and Dominic Wyse
}

Department of Early Years and Primary Education, Institute of Education, University College London, 120 Bedford Way, London WC1H 0AL, UK

(Received 8 July 2014; accepted 3 March 2015)

There has been an increasing focus in policy and practice on adopting inclusive pedagogy as a way of reconceptualising how schools work with children with special educational needs (SEN). The paper considers the split between knowledge and pedagogy inherent in some dominant strains of inclusive pedagogy. Drawing on the 'knowledge turn' in curriculum studies, we argue that although an analytical distinction between knowledge and pedagogy may be useful, too strong a delineation between the two fails to best serve the needs of children with special needs. Specific implications for teacher education in relation to $\mathrm{XEN}$ in England are considered.

Keywords: inclusion; special educational needs; pedagogy; inclusive pedagogy

\section{Inclusive pedagogy and knowledge: addressing the tension}

In the modern classroom, children's needs are diverse, complex and recognised as such; yet, progressive and neo-liberal conceptions of the purpose of activity in the classroom often have an uneasy cogxistence both in the structures of the school and in the mind of the teacher. The tension between instrumentalist approaches to the role of the teacher, and alternative, broader conceptualizations of the purposes of education are often most clearly seen when classrooms contain children perceived as differing from the norm. Children with diagnostic labels such as autism, dyslexia, attention deficit disorder (ADD), or children without a label who simply do not respond in a straightforward way to teaching, present challenges for the development and enactment of pedagogy, curriculum and assessment. If high-stakes test results are seen as the primary driver of an education system, then these children with perceived special educational needs (SEN) can often be seen as an impediment to achieving the tightly defined outcomes, in terms of academic progress, that the curriculum and the assessment framework are supposed to engender. Such anxieties, whether directly or indirectly expressed in the classroom, can frequently lead to the children to whom such labels are applied feeling marginalised and devalued (see Daniels et al. 2003; Daniels and Porter 2007).

The increasingly dominant trend in dealing with difference in the classroom is the adoption of an inclusive pedagogy approach. This exists in a variety of expressions, but an influential variety, certainly in the UK, has been the formulation of Florian and Black-Hawkins (2011). Their work adopts an approach to teaching based on two key

\footnotetext{
*Corresponding author. Email: j.mintz@ioe.ac.uk
} 
propositions. The first is that each child is valued equally by the teacher and the school. The second is that the process of adaptation of the delivery of the curriculum to meet the needs of each child is done from the perspective of all children in the class. Thus, rather than considering the needs of children with special needs as an 'add on', after catering for the needs of the 'median' child, the process of planning and delivery of teaching in the classroom reflects the proposition that all children are of equal value. This is not meant to imply that children have equal needs, nor to deny that there may be (often significant) variation in levels of attention and resource required for different children, rather it is an ideological position, and one that is clearly rooted in sociological critiques of special education, particularly those derived from Foucault $(1975,1977)$, first expressed in disability studies and then in the more specific movement towards inclusion in the education system (see, a.g. Barton 1988; Oliver 1990). This location of inclusive pedagogy as part of a tradition of sociological critique of how difference is conceived of and treated in society is critical for the argument that will be developed in this paper. We will argue that although such critiques have had, and continue to have, a centrally important role in highlighting for teachers the dangers associated with a socially conservative approach to education which ignores difference, they also themselves pose a danger in terms of how knowledge is conceived of and applied in the work of teachers in relation to their work with children with SEN. This is particularly relevant for our focus in this paper on how we should consider the place of knowledge in teacher education in relation to SEN.

\section{Thinking about knowledge}

In highlighting what we conceive these dangers to be, we draw on the 'knowledge turn' in curriculum studies. This turn, particularly stimulated by the work of Young (2008) and others (Young and Muller 2010; Rata 2012), involves a reframing of the relationship between knowledge, curriculum and pedagogy. We argue that the literature in this area can potentially illuminate some of the current debates about how we should best prepare teachers for working with children with SEN.

The knowledge turn focuses on what social realism can tell us about the place of theoretical and expert knowledge in teaching and learning. Young and Muller argue that we can conceive of knowledge as 'sets of systematically related concepts and methods for their empirical exploration' $(2010$, 5). Following Durkheim, these are seen as emergent from, but at the same time not reducible to their historical content. This irreducibility implies both the existence of boundaries between sets of concepts and the possibility of objective standards of judgement about the validity of knowledge based on the pursuit of the scientific method. Although not always directly addressed in the literature, we would argue that in terms of typification, the knowledge that the knowledge turn refers to is primarily propositional knowledge, in Ryle's terms, 'knowledge that' (1945). This might also be referred to as expert or theoretical knowledge (Higgs 2008).

Young and Muller make a distinction between 'under socialised' and 'over socialised' approaches to knowledge. They are particularly critical of the latter, in that it 'reduces epistemology to "who knows" and the identification of knowers and their practices' $(2010,5)$. Rata notes that the dangers of the ' ... relativist idea that knowledge is constructed within the social relations and language of distinct socio-cultural groups' $(2012, \lambda 06)$. Rata particularly points to the dangers of such a focus on 'social knowledge' denying the benefits of knowledge derived from the rational 
thinking of the Enlightenment to socially disadvantaged groups who in fact stand most to benefit from it.

Young and Muller (2010) reject 'post-modernist' approaches to knowledge in favour of a structurally conservative realism, which maintains both the boundaries between disciplines and the necessary objectivity of knowledge, and which in a broad sense can and does tell us independently 'true' things about the world, They make this argument for both the 'hard' and the human sciences. However, their application of the argument to the latter is constrained by a simultaneous rejection of a socially conservative approach to knowledge which maintains educational and societal structures which restrict the availability of this 'powerful' knowledge to the elites within society $(2010,7)$

110 Such a social realist approach presents a rebuttal of conceptions of knowledge about human beings based on Foucault's work, as they are expressed in disability studies, as both the product of particular social and historical events and as constituting modes of objectification through which the human subject becomes known and knows itself. Whilst the social realist formulation accepts that social and historical contexts present a mask which can obscure real differences between individuals (i.e. the acceptance of critique of social conservatism), it implicitly rejects a discursive approach to conceptualising knowledge. Epistemology, in the knowledge turn, is very definitely not based on 'who knows'. It is this critique that we feel also has important implications for teacher education about SEN.

\section{Knowledge and curriculum}

The knowledge turn is primarily designed, on an instrumental level, as a critique of curriculum design in schools. Young and Muller (2010) do not argue that skills and context are unimportant, but that their importance does not outweigh that of empirically derived concepts and methods associated with particular disciplines. Yet, their approach to the place of theoretical knowledge about the human subject is not restricted in its formulation to school curriculum design, and we argue that it can and should be applied to other contexts of teaching and learning. In particular, it could be applied, to the position of theoretical knowledge in the curriculum for teacher education in relation to what teachers need to know about children with SEN. In this context, we will specifically address the contention of Lewis and Norwich (2005), highly influential in terms of practice in teacher education in England, that whilst there may be, in at least some cases, specialist knowledge about SEN, there is no special pedagogy.

\section{Theoretical and tacit knowledge}

In applying the knowledge turn, designed as a critique of the school curriculum, to the 'curriculum' for teacher education for $\mathrm{SEN}$, we recognise that there is a significant extant literature on teacher thinking and teacher research which considers the place of theoretical and expert knowledge in the work of teachers in the classroom and approaches to teacher education (e.g. Clark and Petersen 1986; Shulman 1987; Brown and McIntyre 1993; Turner-Bisset 1999; Clark 2005). Much of this literature builds on the earlier work of Schön (1983) and Polanyi (1962), in its exploration of the relationship between expert/theoretical and tacit/experiental knowledge. As indicated, we argue that the knowledge turn, based on social realism, appears at first reading to have greater affinity with intellectualism (Ryle 1945), or as Fodor (Fodor 
1968) puts it, that tacit knowledge just represents a set of mental functions that we have not yet been able to describe or put in to language. However, the social realist acceptance of the historical and cultural situatedness of disciplinary knowledge, with the emphasis on communities of enquirers as the mode through which knowledge is both maintained and developed (Young and Muller 2010, 12), also points towards an acceptance of a definition of 'disciplinary' knowledge that encompasses tacit and theoretical knowledge in relationship, although the nature of this relationship seems to us somewhat undefined in the social realist literature, especially as they quite clearly eschew a markedly sociocultural or Foulcadian conception of knowledge.

However, we do nat see the focus of the social realist literature, certainly as it relates to our interests in this paper, as being on defining the relationship between techne and episteme either in the school curriculum or in teacher education (see Mintz 2014 for a more detailed discussion of these issues). Rather, as noted, in critiquing 'over socialised' approaches to knowledge, it serves the function of highlighting the dangers of an approach to the curriculum which underemphasises the importance of theoretical knowledge and overly emphasises both the historical and social contexts of knowledge production (who knows rather than what is known) and an overly constructivist approach to knowledge acquisition.

\section{Knowledge and SEN}

Barton's (1988) demarcation of two opposite poles, the sociological and psychological positions on SEN are relevant to our consideration of the place of theoretical knowledge in the work of teachers with children with SEN. In the psychological position, SEN are conceived of in terms of discrete diagnostic categories. Accordingly, it is specific theoretical knowledge about these that teachers require. In psychological orientations, at least in Barton's analysis, this is conceived of showing us how we can make up the deficit between the typical population and the population in the sub-category, so that they can come closer to meeting particular outcomes considered desirable in the education system. Barton's sociological critique deconstructs outcome as a mode of objectification, which is produced as an interaction of individual and system. It then follows that less emphasis is placed on diagnostic (or expert/theoretical knowledge) and more on either tacit/experiential knowledge, that is, coming to know the child as an individual. At the same time, when outcome is deconstructed, then a variety of possible outcome 'measures' (or educational purposes) can be seen to have value - the effusive drawing of a child with dyslexia has as much import as the analytical essay of his peers.

There is also a vocal, parallel strand in the literature which places little importance on theoretical knowledge about SEN, but rather stresses the necessity of teachers having the correct attitude to (and/or beliefs about) inclusion (see, e.g. Leatherman and Niemeyer 2005; Avramidis and Kalyva 2007). In both cases, where outcome is seen as a product of an interaction of individual and system, having the correct attitude is seen as important rather than theoretical knowledge about particular diagnostic 190 categories.

The knowledge turn seems highly applicable here. Young and Muller (2010) refer to the necessary objectivity of theoretical knowledge, for example, about knowing particular concepts and their methodological derivation and empirical demonstration in the physical sciences. This argument, it would seem to us, is equally applicable, for example, to the necessary objectivity of theoretical knowledge about stages of child development when dealing with children who do not follow typical development 
trajectories. It is knowledge, we will argue, that is in danger of being underemphasized in the education of teachers working with children with $\mathrm{S} E N$.

\section{Policy trends}

Tensions between sociological and psychological positions on SEN have been reflected in trends in policy development in relation to both service provision for children with SEN and the professional development of their teachers. In England, the ideological move towards inclusion heralded by the influential Warnock report (Warnock 1978), and to a significant extent supported by the New Labour government of 1997-2010, has to some extent been reversed by the Conservative-Liberal coalition government since 2010. Their reversal of New Labour's programme of special school closures is a case in point. The Children and Families Act (Department for Education 2014) has also heralded greater emphasis on the role of specialist skills and knowledge for teachers and other care professionals working with children with SEN. In the USA, although there is a much more clearly embedded tradition of specialist training for special educators, since the passing of the Individuals with Difficulties Education Act (IDEA) in 1997, there has also been growing debate about mainstreaming (Kavale 2002) and the extent to which specialist knowledge, restricted to special education teachers, is the best way to achieve good outcomes across different groups of children (Brownell et al. 2005; Jones and West 2009). These policy issues in the USA are linked to an ongoing debate as to whether developing specific understanding about particular diagnostic categories, and associated specific teaching strategies, makes teachers more effective practitioners.

It is important to stress the historical differences between the approach to specialist theoretical knowledge about special needs taken in England as compared to other countries. The USA and many European countries have a tradition of specialist initial teacher training for SEN teachers, who would in the past go on to teach in specialist provision for children with SEN, although there is an increasing trend for such teachers to work in mainstream settings as well (Hegarty 1998; Hodkinson 2009). In contrast, there has never been any established tradition of specialist education for teachers of SEN, at least in initial teacher training, in the UK (Hodkinson 2009). Possible reasons for the lack of specialist education in the UK could be that since 1980 , UK education policy has been very heavily influenced by a sociological discourse on special education, and it is also possible that the relatively low levels of funding for initial teacher training in the UK may be implicated. In England, teacher training institutions have been strongly influenced by Lewis and Norwich's (2005) argument that there is no such thing as a special needs pedagogy. This is of crucial importance for the education of teachers. An approach common in many teacher training institutions implies that teachers need to know about broad principles of inclusive pedagogy, but not specialist knowledge, for example, about autism, ADD or dyspraxia.

\section{What is the evidence for a lack of theoretical knowledge?}

To some extent, it is difficult to identify clear evidence as, we would argue, the dominance of a sociological position on knowledge within the field of SEN means that there is relatively little literature that focuses on the assessment of teacher knowledge or empirical evaluation of effects resulting from its lack. Putting this another way, the interpretation of empirical data about knowledge in this field is predicated on an 
ideological split between sociological and psychological (or 'over socialised' and 'under socialised') positions. Nevertheless, some literature does explicitly recognise the effects of a lack of knowledge about diagnostic categories in teacher education on inclusive practice. For example, Osler and Osler (2002) presented data to indicate that particularly for some impairments, the level of understanding about those conditions and what implications they can have for teaching strategies makes a significant difference to the effectiveness of the teacher in meeting the needs of those children. Weddell (2008), drawing on government statistics on academic outcomes for children with SEN, argues that student teachers in England and Wales are generally unprepared for meeting the needs of those with SEN and concludes that emphasis in teacher education on subject knowledge rather than on child development and the psychology of learning meant that teachers were not well equipped for supporting children with SEN. Furthermore, the UK House of Commons Education and Skills Select Committee (2006) which undertook an in-depth review of SEN provision in schools, and received representations from a range of stakeholders, including teachers, parents, other professionals and special interest groups, noted the need for teachers to receive significantly greater input on the psychology of child development both generally and in relation to particular diagnostic categories. Yet, many theorists writing on inclusive pedagogy reject this position and maintain that a focus on knowledge related to diagnostic categories is not something relevant for teachers working with children with SEN. In order to illuminate this, we focus in particular on Lewis and Norwich's (2005) analysis, which we would contend has been influential in thinking on teacher education in the academy.

\section{Special teaching?}

Lewis and Norwich's (2005) book Special Teaching for Special Children, includes a set of chapters, written by a series of experts in various diagnostic categories, including autism, dyslexia and moderate learning difficulties, each of whom reviews research evidence and best practice approaches for each category. Based on these reviews, Lewis and Norwich conclude that with the exception of specialist services for hearing and visual impairment, there is no good evidence for the existence or effectiveness of a special pedagogy, by which they mean a particular set of pedagogic strategies specific to a particular diagnostic category. They go on to argue that services for children with SEN would be more effective if we consigned the idea of special pedagogy to history, and conclude that 'the traditional special needs categories used in the UK, and internationally, have limited usefulness, in the context of planning or monitoring, teaching and learning in most areas' $(2005,220)$.

The authors also make a blunt distinction between knowledge and pedagogy. There is, they argue, clearly particular knowledge about specific categories of need, but no special pedagogy. In making such a marked distinction between knowledge and pedagogy, Lewis and Norwich seem to be adopting a somewhat extreme approach to thinking about professional practice. Lewis and Norwich's distinction appears to run counter to the rich seams of argument about teacher thinking and development in the literature, as discussed above, building on Schön's work, which see theoretical knowledge and tacit knowledge and the application of strategies by a professional, as being in some fashion of relationship, often considered as a dialectic conversation (Elbaz 1983; Schön 1983; Nias 1989). It is hard to find evidence to support the alleged split between knowledge and pedagogy in the practice of teachers. Neither is it reasonable 
to argue that social realist approaches to knowledge imply such a hard split between knowledge and pedagogy. Young, in arguing for a structurally conservative position on knowledge, only applies this at an analytical level, recognising that, in practice, they are inevitably linked.

Yet, Lewis and Norwich use their expert reviews to support their contention that there is specialist knowledge, but no special pedagogy. For example, they refer to Porter (2005) writing about severe learning difficulties, who reviewed a number of studies on working memory, and concluded that:

... In considering the implications of this research one needs to take into account familiarity of material and individual differences but we can hypothesize that individuals will respond better to visual material and small chunks of information especially when this is presented in auditory form and that they need to be helped to use strategies such as rehearsal .... (2005, $\left.\mathbf{\lambda}^{6 / 57}\right)$.

Similarly, Lewis and Norwich refer to Read (2005), who discusses a number of multisensory intervention programmes, focusing particularly on Walker's (2000) review, which concludes, according to Read, that:

... the student with dyslexia may need more input and a different structure of teaching from other children. It also presupposes that the teacher should be aware of, (a) the factors associated with the acquisition of literacy, (b) the particular difficulties in literacy that can be noted in dyslexic children, (c) the principles of multisensory teaching, (d) the importance of selecting clear and coherent teaching aims and, (e) an awareness of the important role-played by both pre-reading strategies and proofreading, as a post-writing strategy, in the teaching of students with dyslexia .... $(2005,141)$

Read notes the contested and sometimes uncertain nature of experimental studies in this area - a theme which runs through many of the chapter contributions. However, hoth in this case, and in Porter's (2005) work, it seems quite clear that they are suggesting particular teaching strategies that relate to these particular groups of children, and which it is at least conceivable are different to strategies which might be considered for other 325 children.

Sociological critiques of special education, a tradition within which Lewis and Norwich's work can be located, and 'over socialised' approaches to knowledge in curriculum studies, are derived from Rostmodernist ideas (particularly Foucault) about conceptualisation of difference. Both perspectives downplay the importance of knowledge and, as Young and Muller (2010) argue, carry the risk of denying groups in society access to the benefits of the scientific approach. However, when the critique of postmodernism is applied to SEN, it becomes difficult to see pedagogy as having a scientific component to it. This may be one reason why in Lewis and Norwich's work, as well as some of the broader literature on inclusive education, knowledge (i.e. science) and practice become split and seen as separate entities.

The knowledge turn in curriculum studies can inform how we should conceptualise the place of theoretical knowledge in the education of teachers in relation to SEN. The critique that Young applies to over socialised approaches to knowledge in curriculum studies can be applied to over socialised approaches to knowledge in relation to teacher 340 education and SEN. Just as Young rejects a simplistic socially conservative view of the position of knowledge, we accept both the force and the utility of sociological critiques in pointing gut how the historical context of the application of knowledge in the human sciences has in the past, and can in the future lead to the devaluing of people when 
particular labels are applied to them. This is salient when thinking about SEN, as instrumentalist approaches that simplify the human condition and oversimplify complex human experience, whether as diagnostic categories or as tightly defined assessment measures such as GCSE results or PISA scores, do not full reflect the value of the individual. They are inevitably in conflict with an inclusive approach that seeks to value every child.

Neither do we disagree with Lewis and Norwich's broad point that in many (but crucially far from all) cases of children with SEN, understanding about effective pedagogy predicated on understanding the needs of the individual child, rather than detailed knowledge about diagnostic categories, is central to effective practice with children with special needs. At the same time, we would argue that such a pedagogy is likely to be more effective if it includes an openness to investigating what psychology may have to tell us about those individual needs, which will include particular pedagogic strategies specific to particular diagnostic groups. In this sense, we argue that there is indeed, in many cases, a special pedagogy for $\mathrm{SEN}$.

What the knowledge turn in curriculum studies points towards is an intermediate perspective in relation to the knowledge required for teachers of children with SEN, which we can see to a certain extent in current policy in England. For example, in the terms of the Children and Families Act, there is some recognition that a part of special education is recognising, for example, that the human sciences can provide evidence as to how we can improve the life chances of certain groups of children. Thus, the child with autism should be encouraged to engage in 'neurotypical' social communication if that means that he/she will be able to get a job, get married and have fulfilling relationships in society as it is. From such a perspective, specific knowledge about diagnostic categories has an important place in the work of teachers. In contrast, a split between knowledge and practice, based perhaps on an irrational fear of any level of instrumentalism in education, has dangers. Science, including psychology offers important knowledge of relevance to teaching. As we progress in to the twenty-first century, the possibilities for developmental psychology and neuroscience to offer insights into human activity, and specifically about how different children might learn, are becoming increasingly difficult to ignore. We need to be careful in interpreting this science, and in some ways, it is probably a healthy strategy to engage in contesting its implications, but to suggest that it does not have implications for how we think about the human mind and its development is not supportable.

It is also important to note another danger inherent in the splitting of knowledge from pedagogy in relation to special needs. Lewis and Norwich argue that we do not need to know about special pedagogy, but that there is 'split off' knowledge about particular diagnostic categories, which we might want to know about. However, this is a fine-grained argument, which may be open to misinterpretation, particularly in an education system where a sociological discourse facilitates, at least for some, suspicion of the role of psychology in education, The message that teachers might receive is that they do nat need to know anything about what science can tell us about diagnostic categories. This could mean that they will not be in a position to make use of particular pedagogic strategies relevant to the needs of specific diagnostic groups.

\section{Conclusions}

There are serious questions about how effectively teacher training in England currently prepares teachers for working with children with ҚEN. Important evidence of this has 
been seen in a number of reports going back to the UK House of Commons Education and Skills Select Committee (2006). The Committee concluded that there was a lack of emphasis on training in SEN in both initial teacher education and Continuing Professional Development frameworks and recommended that 'SEN training should become a core, compulsory part of initial teacher training for all teachers' (70). No doubt, partly in response to this report, and other policy reports with similar conclusions such as the Lamb Enquiry (DCSF 2009), government policy in the UK since 2008 has placed more emphasis pn SEN training for teachers, with a range of, although patchily implemented, initiatives, including a national training programme for Special Educational Needs Coordinators (Training and Development Agency for Schools 2010) and a greater emphasis an SEN in initial teacher training in the Children and Families Act (Department for Education 2014). Further work is needed on the most appropriate teaching for all children, and we need to prepare teachers to understand how they can construct a pedagogy for the individual children with SEN that they work with based on their personal knowledge of the child and a clear understanding of what we usefully know about particular diagnostic categories. The reforms to SEND provision in England following on from the Children and Families Act (2014) have provided an 410 opportunity for this to be given greater focus in policy implementation. For example, the reference to teacher understanding of the implications of research evidence for practice in the revised SEND Code of Practice (Department for Education 2014) gives stronger emphasis to the need to understand what science can tell us about practice in relation working with children with SEN. However, if this is to be translated in to practice in schools, then teacher educators in both universities and schools will need to develop a more nuanced understanding of the place of special pedagogy in working with children with SEN.

We agree that individual differences, the individual personality, likes, dislikes, strengths and difficulties of a child, are always likely to be what is most important. 420 However, what the knowledge turn in curriculum helps us to consider is the risk of separating knowledge from pedagogy in special education to the degree that essential knowledge may not be weighed up, and theoretical knowledge organised around diagnostic categories does have really important and useful things to tell us about how to do the best for children with particular needs.

425 Inclusive pedagogy, with its roots in postmodernist approaches to conceptualising difference, although offering an important critique of how we think about difference, also runs the risk of downplaying the importance and possible benefits of scientific knowledge in the work of children with SEN. In this paper, we have considered the important question posed by Lewis and Norwich as to whether there is a special pedagogy for SEN. We argue that the knowledge turn in curriculum studies has refocused attention on the place of theoretical knowledge, particularly knowledge derived from science in a broad sense, in education. We differentiate between an analytical as opposed to descriptive split between knowledge and pedagogy, and point out that the proposition that knowledge and pedagogy can be completely split off from each other in inclusive pedagogy runs the risk of denying the potential benefits of the human sciences to particular groups of children who may actually have need of it.

Although recognising that the knowledge turn has arisen in the context of the school curriculum, we argue that the theoretical arguments of social realism on which it is based are directly parallel to and have similar implications for teacher education in relation to SEN. Applying the knowledge turn in this way leads us to the conclusion that we should, in policy terms, aim to facilitate the professional development of 
teachers who can flexibly make use of a concept of special pedagogy involving both theoretical knowledge about specific diagnostic categories and their experientially derived 'knowledge' of the individual child.

\section{Notes on contributors}

\section{References}

Avramidis, Elias, and Efrosini Kalyva. 2007. "The Influence of Teaching Experience and Professional Development on Greek Teachers' Attitudes towards Inclusion." European Journal of Special Needs Education 22 (4): 367-389.

Barton, L. 1988. The Politics of Special Educational Needs. London: Routledge, 219. Retrieved from http://books.google.com/books?id=wChe9UVIVnYC\&pgis=1

Brown, S., \& McIntyre, D. 1993. Making Sense of Teaching. London: Open University Press.

Brownell, Mary T., Dorene D. Ross, Elayne P. Colón, and Cynthia L. McCallum. 2005. "Critical Features of Special Education Teacher Preparation: A Comparison with General Teacher Education." The Journal of Special Education 38 (4): 242-252.

Clark, M. 2005. "Asking the Right Questions about Teacher Preparation." In Teacher Thinking and Professional Action, edited by P. Denicolo and M. Kompf. New York: Routledge.

Clark, M., and P. L. Petersen. 1986. "Teacher Though Processes." In Handbook of Research in Teaching, edited by M. C. Wittrock, 3rd ed. New York: Macmillan.

Daniels, H., T. Cole, E. Sellman, J. Sutton, J. Visser, and J. Bedward. 2003. Study of Young People Permanently Excluded From School, DfES Research Report RR405. London: Department for Education and Skills.

Daniels, H., and J. Porter. 2007. "Learning Needs and Difficulties among Children of Primary School Age: Definition, Identification, Provision and Issues." In The Cambridge Primary Review Research Surveys, edited by R. Alexander, R. Doddington, C. Gray, L. Hargreaves, and L. Kershner, 217-240. London: Routledge.

Department for Education. 2014. "Children and Families Bill 2014." England and Wales, Accessed May 1, 2014. http://www.education.gov.uk/a00221161/

Department of Education. 2014. "Code of Practice for Special Educational Needs." Accessed February 22, 2016. https://www.gov.uk/government/publications/send-code-of-practice-0to- 25

Elbaz, F. 1983. Teacher Thinking: A Study of Practical Knowledge. London: Taylor \& Francis.

Fodor, J. A. 1968. "The Appeal to Tacit Knowledge in Psychological Explanation.” The Journal of Philosophy 65 (20): 627-640.

Foucault, M. 1975. The Birth of the Clinic: An Archaeology of Medical Perception. New York: Vintage Books.

Foucault, M. 1977. Madness and Civilization: A History of Insanity in the Age of Reason. London: Tavistock.

Hegarty, S. 1998. "Challenges to Inclusive Education: A European Perspective." In Inclusive Schooling: National and International, Perspectives, edited by S. J. Vitello and D. E. Mithaug. London: Routledge.

480 Higgs, J. 2008. Clinical Reasoning in the Health Professions. London: Elsevier Health Sciences.

Hodkinson, Alan. 2009. "Pre-service Teacher Training and Special Educational Needs in England 1970-2008: Is Government Learning the Lessons of the Past or Is It Experiencing a Groundhog Day?" European Journal of Special Needs Education 24 (3): $277-289$.

House of Commons Education and Skills Select Committee. 2006. Special Educational Needs: Third Report of Session 2005-2006. London: Parliament.

Jones, Phyllis, and Elizabeth West. 2009. "Teacher Education: Reflections upon Teacher Education in Severe Difficulties in the USA: Shared Concerns about Quantity and Quality." British Journal of Special Education 36 (2): 69-75.

Kavale, Kenneth a. 2002. "Mainstreaming to Full Inclusion: From Orthogenesis to Pathogenesis of an Idea." International Journal of Disability, Development and Education 49 (2): 201-214. 
Lamb, B. 2009. Lamb Inquiry: Special Educational Needs and Parental Confidence. London: Department of Children, Schools and Families.

Leatherman, J. M., and J. A. Niemeyer. 2005. "Teachers' Attitudes toward Inclusion: Factors Influencing Classroom Practice." Journal of Early Childhood Teacher Education 26 (1): $23-36$.

Lewis, A., and B. Norwich. 2005. Special Teaching for Special Children? Milton Keynes: Open University Press.

Mintz, J. 2014. Professional Uncertainty, Knowledge and Relationship in the Classroom: A Psychosocial Perspective. London: Routledge.

Nias, J. 1989. Primary Teachers Talking. London: Routledge.

Oliver, M. 1990. The Politics of Disablement. London: Macmillan.

Polanyi, M. 1962. Personal Knowledge: Towards a Post-critical Philosophy. Psychology Press.

Porter, J. 2005. “Severe Learning Difficulties.” In Special Teaching for Special Children? edited by A. Lewis and B. Norwich, 53-66. Milton Keynes: Open University Press.

Rata, E. 2012. "The Politics of Knowledge in Education." British Educational Research Journal 38 (1): 103-124. doi:10.1080/01411926.2011.615388

Read, G. 2005. "Dyslexia.” In Special Teaching for Special Children? edited by A. Lewis and B. Norwich, 138-149. Milton Keynes: Open University Press.

Ryle, G. 1945. "Knowing How and Knowing That: The Presidential Address." Proceedings of the Aristotelian Society 46: 1-16.

Schön, D. A. 1983. The Reflective Practitioner: How Professionals Think in Action (Vol. 116, 374). London: Temple Smith, Basic Books.

Shulman, L. S. 1987. "Knowledge and Teaching: Foundations of a New Reform." Harvard Educational Review 57 (1): 1-22.

Training and Development Agency for Schools. 2010. "The National SENCO Award." Accessed May 1, 2014. http://www.education.gov.uk/schools/careers/traininganddeve lopment/b00201451/sen-skills/advanced-skills

Turner-Bisset, R. 1999. "The Knowledge Bases of the Expert Teacher." British Educational Research Journal 25 (1): 39-55. doi:10.1080/0141192990250104

Walker, J. 2000. "Teaching Basic Reading and Spelling." In Dysexia Practice, edited by J. Townend and M. Turner, 93-129. New York: Springer.

Warnock, H. 1978. "The Warnock Report (1978)." Special Educational Needs Report of the Committee of Enquiry into the Education of Handicapped Children and Young People. London: HMSO.

Young, M. 2008. "Bringing Knowledge Back." In From Social Constructivism to Social Realism in the Sociology of Education. Abingdon: Routledge.

Young, M. 2014. "What is a Curriculum and What Can it Do?" The Curriculum Journal 25 (1): $7-13$.

Young, M., and J. Muller. 2010. "Three Educational Scenarios for the Future: Lessons from the Sociology of Knowledge.” European Journal of Education 45 (1): 11-27. 